\title{
Hans Ulrich Gumbrecht - Atmosfera, ambiência, Stimmung: sobre um potencial oculto da literatura
}

Trad. Ana Isabel Soares. Rio de Janeiro: Contraponto; Ed. PUC-Rio, 2014

Matheus de Brito ${ }^{1}$

“'É correto que o ensaísta busque a verdade', escreveu [Lukács], 'mas deve fazê-lo à maneira de Saul. Saul partiu em busca dos burros de seu pai e descobriu um reino; assim será com o ensaísta - aquele que é de fato capaz de procurar a verdade; encontrar, no final de sua busca, aquilo que não procurava: a própria vida'" (p. 29). De igual modo Hans Ulrich Gumbrecht discute o que seria a melhor forma de estudar literatura - como um eco distante, a citação soa ou uma confissão ou uma despedida de questões anteriores. Em Atmosfera, ambiência, Stimmung: sobre um potencial oculto da literatura, o que está "oculto" se revela no esforço de Gumbrecht para redimir certos aspectos de sua experiência literária excluídos durante seus dias na Escola de Constança na década de 1970 e na virada dos anos 1990, ao longo do desenvolvimento das materialidades da comunicação.

O livro é editado pela Contraponto e pela Editora PUC-Rio, que já antes publicaram Produção de presença (2004). A tradução, de Ana Isabel Soares, que também trabalhou em Depois de 1945 (2014), segue muito próxima à tradução americana (Atmosphere, mood, Stimmung, publicada em 2012 pela Stanford University Press) no título como no texto. Originalmente, Stimmung Lesen, que poderia ser "ler por Stimmung", o título indica a composição do livro, uma série de breves ensaios sobre literatura escritos para o Frankfurter Allgemeine Zeitung [Jornal Geral de Frankfurt].

Embora o núcleo teórico do primeiro capítulo quase sirva como tal, a obra dispensou uma "introdução" e as usuais notas de rodapé. Nas páginas finais, há algumas notas afetivas, e uma bibliografia mínima leva a crer que o autor citou quantos livros. De qualquer modo, se surpreende a ausência de referências acadêmicas - algo estranho ao espírito escolar de Gumbrecht -, não nos surpreenderíamos se ele o tivesse feito como uma provocação aos leitores escolares; como parti

\footnotetext{
${ }^{1}$ Doutorando em materialidades da literatura na Universidade de Coimbra, Portugal, e em teoria e história literária na Universidade Estadual de Campinas (UNICAMP), Campinas, SP, Brasil. Email: debrito@gmx.com
} 
pris, evitar um "acadamês" fluente parece ser a única forma que o autor enfim encontrou de fazer jus à sua própria crítica.

Quer o próprio Gumbrecht prescinda de um esboço biográfico por qualquer razão - como se espera duma introdução -, quer tome como dado seu reconhecimento na República das Letras, uma leitura adequada da Stimmung exige uma breve retrospectiva, se quisermos que seus "poderes" e possibilidades sejam liberados. O jovem Sepp Gumbrecht foi dos pioneiros da estética da recepção; por boas razões, distanciou-se da figura de H. R. Jauss, seu mentor, e direcionou suas preocupações (e sua investida altamente complexa) ao que seria a exterioridade da literatura. Esse movimento centrífugo levou-o à plena dissensão com a ideia de "ciência da literatura" e com a letra morta das tradicionais "ciências do espírito", sob o signo do "não hermenêutico".

Em contraste com o triste "princípio de imanência" que permeia os estudos literários, como poderia Sepp Gumbrecht alcançar aquela "exterioridade" viva que ele mirou através das limitações do conhecimento? Seu percurso é de recusas e refutações: a estética da recepção pareceu-lhe uma heurística de regras de interpretação, a Desconstrução surgiu nostalgicamente imersa em falsas querelas, o Novo Historicismo nunca pareceu confiável e, por fim, os Estudos Culturais estavam comprometidos $a b$ ovo com tornar-se num formato barato de prosa, em função de sua negligência epistemológica. Até mesmo o hiato entre o ânimo de Gumbrecht e a materialität (Materialities of communication, 1994 [1989]) e a estética (Gumbrecht, 2004) parece revelar algum desencantamento em relação ao (seu próprio) programa anterior. Contudo, talvez haja mais do que indisposição nessas desilusões - ansiedade, talvez, por uma diferença enfática num porvir dos estudos literários? Disse-se, na altura de Produção de presença, que Gumbrecht era um homem tenaz, um homem que em meio à selva da cultura contemporânea se recusava a subsidiar o ventriloquismo da atual crítica, tão propensa a enfatuar-se de sua pretensa criticidade. Suas rejeições, assim pensadas, parecem configurar a busca que ora culmina no livro sobre Stimmung.

Mas aí está: Gumbrecht defendeu o fim da "teoria" e trouxe outro livro, em nome de alguma justiça mais alta, de teoria. Por isso o autor toma como ponto de partida rixas antigas. No capítulo introdutório, "Ler em busca de Stimmung: como pensar hoje na realidade da literatura", o autor acusa uma cumplicidade entre a desconstrução 
americana e os estudos culturais, a qual consiste na ideia atávica de que a obra literária tem, ontologicamente, um caráter representativo ou construído. O falso antagonismo é um dos sintomas da atual problemática da theory americana: de um lado, há questões metafísicas em causa, do outro, espera-se algum saldo sociopolítico. Já que toda a theory partilha o gesto fundamental do ler por um sentido (qual seja), Gumbrecht descarta mesmo a tentativa de reconciliar esses dois aspectos: resolver o dilema do intrínseco vs. o extrínseco ao explorar suas tensões internas não é senão um impasse, já que a literatura continuaria como mero material para produção de sentido e circulação de discursos na indústria da consciência. Contudo, se seguirmos Gumbrecht em suas reflexões sobre materialidade e estética e se aceitarmos a ideia de que a literatura é irredutível a seus aspectos construídos - sendo imune, assim, à desconstrução - e, como tal, se percebermos o tipo diferente de experiência aí implicada, o que acontece?

Quase como Walter Benjamin proporia, a ideia de "ler por Stimmung" é, antes de qualquer expectativa proposicional ou enquadramento semântico, fazer surgir da obra literária sua natureza "coisal" - fazê-la surgir como algo no mundo. Esse caráter, também referido como presença - o conceito para a percepção intransitiva/intrusiva de algo através da perda de sua autoevidência (i.e., algo surge mais presente conforme menos faz sentido nas condições em que se dá) -, torna-se um elo histórico em Atmosfera, ambiência, Stimmung. Porque a obra é uma coisa no mundo e não um objeto mudo perante falatórios subjetivos, sua exterioridade - o meio social e cultural de sua concepção - se condensa na sua substância através da mediação estética, na prosódia e nas escolhas lexicais como nas falhas técnicas, em minúsculas inflexões de todo o tipo. Se tal ideia per se não propõe nada de novo, abre-se um abismo entre a ideia de Stimmung e alguma sociologia da literatura quando pensamos em "ler por diferencialidade", isto é, se tomamos Stimmung como uma mediação de fenômenos não relacionados, uma forma de ler através de fissuras.

A propósito de sua "coisidade", se o milieu se inscreve numa obra não apenas de maneira representacional, isso implica que a experiência de algo que vá além da semântica surge apenas na qualidade de algo não proposicional, algo como uma "atmosfera" ou "disposição" que não pode ser apreendida - nem recusada como uma ilusão, já que sua aparição como tal é a condição da coisa - pela resolução de sua coerência estrutural. A estética e a história fundem-se numa única e 
imediata experiência (o alemão Erfahrung é um conceito que inclui uma dimensão de temporalidade), ou "aquilo que nos afeta no ato da leitura envolve o presente do passado em substância - e não um sinal do passado, nem a sua representação" (p. 25). É aí que somos levados pela Stimmung: a experiência literária não é a decodificação de qualquer verdade embaralhada em superfícies textuais, mas um movimento no interior de uma parada, uma suspensão por meio da qual o leitor "de modo afetivo e corporal" (p. 30) toma parte em atmosferas e disposições, numa vida que ao mesmo tempo é e não é a sua. A retirada da representação e de sua lógica não implica um retorno ao historicismo nem à intencionalidade autoral. Porque o que se quer não é abolir, mas criticar os conceitos em nome daquilo que eles falham em alcançar, a ideia de Stimmung diz da possibilidade de tematizar essa "distração concentrada" por meio da qual nós somos tocados pela alteridade desses distantes presentes "como se de dentro" (p. 32). Aqui se deve indicar, porém, que o título brasileiro não faz jus ao conceito de Stimmung: usar o título americano como modelo sem notar que mood (humor, disposição) e atmosphere (atmosfera) referem-se a esse dentrofora que colide na experiência estética, considerar uma simples diferença entre "atmosfera" e "ambiência" - nenhuma das quais exprime esse "de dentro" que é a própria vida da obra literária -, não é só um mau título, é esquecer mesmo o que está em causa na noção.

A primeira parte do livro, "Momentos", dedica-se à literatura e provê o leitor de um certo tipo de exemplos escolares. Em vez das usuais práticas interpretativas (explicação de texto, leitura cerrada, análise), eles são apresentados como breves ensaios mistos ou comentários: sua proliferação não implica, como na atividade interpretativa, a obliteração do objeto a que eles visam; ao contrário, propõe o autor, o comentário implica uma intensificação da "concretude intensa da experiência que a obra possibilita" (p. 99). Contudo, tal como há formas de interpretação, há também formas de comentário. Se, por um lado, a intenção de Gumbrecht é oferecer exemplos de como ler em busca de "atmosferas", por outro, ele normalmente apela a um tipo discursivo tradicional, que visa produzir uma coerência (supostamente autorizada pelo próprio método), assim dando a volta à fragilidade daquilo que pressupõe. A leitura da disposição ou atmosfera às vezes faz crer que há realmente uma tal coisa como a disposição ou atmosfera. Essa discrepância - entre a experiência que ele apresenta e a que ele 
gostaria de representar - talvez resulte de seus objetivos pedagógicos e de sua recusa a reduzir a possibilidade do discurso crítico a um jogo literário à la desconstrução. Bem considerado, porém, o imperativo à comunicação e as regras para se alcançar um claro e distinto entendimento acabam empobrecendo o que foi doutro modo apresentado como o "potencial oculto", enquanto a coerência residual oculta algum gap conceitual ou retórico. A obra, podemos pensar, não é algo simplesmente "construído" a ser desconstruído, como quer Gumbrecht, mas a Stimmung não goza do mesmo estatuto. Talvez outro estilo discursivo, apesar do esforço já feito por afastar-se da autoridade escolástica, fizesse maior justiça à ideia.

Ou sua inclinação a um estilo mais intuitivo não é afinal tão intuitiva - especialmente considerando a densidade de alguns dos exemplos de leitura - ou o autor não foi capaz de elaborar uma apresentação adequada do próprio programa. De fato, seus ensaios breves são suaves e agradáveis ao leitor acadêmico, no entanto é como se Gumbrecht tivesse dado cabo do procedimento logo após alcançar o resultado. $\mathrm{O}$ programa é interessante, sim, mas no fundo não é muito mais que uma revival da crítica impressionista - normalmente, pasmem!, associada à escrita jornalística. É uma tarefa urgente elaborar uma terceira alternativa discursiva, recusar a atual obrigação de escolher entre mostrar (afetos) ou descrever (estruturas). Será que não é possível, de um modo não pós-modernesco, como o autor gostaria, apresentar a intuição como esse elemento essencial da atividade de leitura, inscrevêla? O tabu concernente à intuição, como se sabe, se consolidou como um mal necessário à legitimação discursiva dos estudos literários na universidade, mas ainda hoje, quando essa legitimidade já nem se põe em causa (às vezes, com a má consciência de quem pensa que o estudo da literatura não serve a nada além da produção acadêmica), o retorno da intuição deveria se dar com uma transformação geral, uma refuncionalização (diria Brecht) da práxis intelectual. Se alguém entende o que está realmente em jogo na rejeição de uma hermenêutica tradicional, Atmosfera, ambiência, Stimmung é Gumbrecht no seu melhor, lançando uma luz sobre seus insights anteriores. Apesar de seus comentários falharem, é importante notar seu esforço em direção a uma diferença que de fato possa fazer diferença.

É inútil relembrar que a expectativa do leitor é decisiva na avaliação da qualidade de seus - de Gumbrecht como do leitor - "Momentos"; ou, 
como o autor põe de uma maneira quase apologética, "não existe um enfoque 'correto' quando se lê poesia" (p. 66). A leitura literária é por definição intuitiva e dificilmente o "típico" leitor transformaria sua própria (e inconsciente) atenção ao Stimmung numa rede de arrasto conceitual - somente acadêmicos são competentes o suficiente para tal. Essa excessiva autoevidência, apesar disso, labora a favor da ideia de que a vida intelectual não se deve restringir à atividade mental incorpórea. A seção final do livro, "Situações", verdadeira proof of concept, mostra que a ausência de um enfoque "correto" é a condição sine qua non de compreender construtos intelectuais em seus aspectos mundanos e, sobretudo, de demonstrar que consciência e reflexão são capazes de restituir o imediatismo da experiência. A questão final é a possibilidade de experienciar a própria vida além dessas meras trocas informacionais que nós chamados de comunicação, que vão da atividade acadêmica aos mexericos cotidianos. Pode-se dizer, assim, que uma reflexão segunda sobre a atividade literária diz respeito a liberar a vitalidade que a literatura tem em sua mundanidade implícita. Esta pode ser reconhecida como a própria "atmosfera" ou "disposição" da leitura de Stimmung de Gumbrecht: o cansaço de uma experiência cotidiana em si mesmo mediada até o ponto da desaparição da concretude do mundo e, como uma dedicação incondicional à ideia de uma vida incondicional, um esforço de considerar as coisas da perspectiva da diferencialidade.

\section{Referências}

GUMBRECHT, Hans Ulrich; PFEIFFER, K. Ludwig (Org.) (1994[1989]). Materialities of communication. Stanford: Stanford University Press.

GUMBRECHT, Hans Ulrich (2004). Produção de presença. Trad. Ana Isabel Soares. Rio de Janeiro: Contraponto; Ed. PUC-Rio.

GUMBRECHT, Hans Ulrich (2012). Atmosphere, mood, Stimmung: on a hidden potential of literature. Stanford: Stanford University Press.

GUMBRECHT, Hans Ulrich (2014). Depois de 1945: latência como origem do presente. Trad. Ana Isabel Soares. São Paulo: Ed. UNESP. 